Supporting information for:

\title{
DNA Clutch Probes for Circulating Tumor DNA Analysis
}

Jagotamoy Das, ${ }^{1}$ Ivaylo Ivanov, ${ }^{1}$ Edward H. Sargent, ${ }^{2}$ Shana O. Kelley ${ }^{1,3}$

${ }^{1}$ Department of Pharmaceutical Sciences, Leslie Dan Faculty of Pharmacy, University of Toronto, Toronto, Canada M5S 3M2, ${ }^{2}$ Department of Electrical and Computer Engineering, Faculty of Engineering, University of Toronto, ${ }^{3}$ Department of Biochemistry, Faculty of

Medicine, University of Toronto, Toronto, ON, Canada M5S 3M2

Index:

Supporting Figure 1: Concentration dependence of electrochemical DCP assay

Supporting Figure 2: Au plating curves

Supporting Figure 3: Comparison of different sensors at same and different chips.

Supporting Table S1. Melting temperature of different duplexes for KRAS detection. 


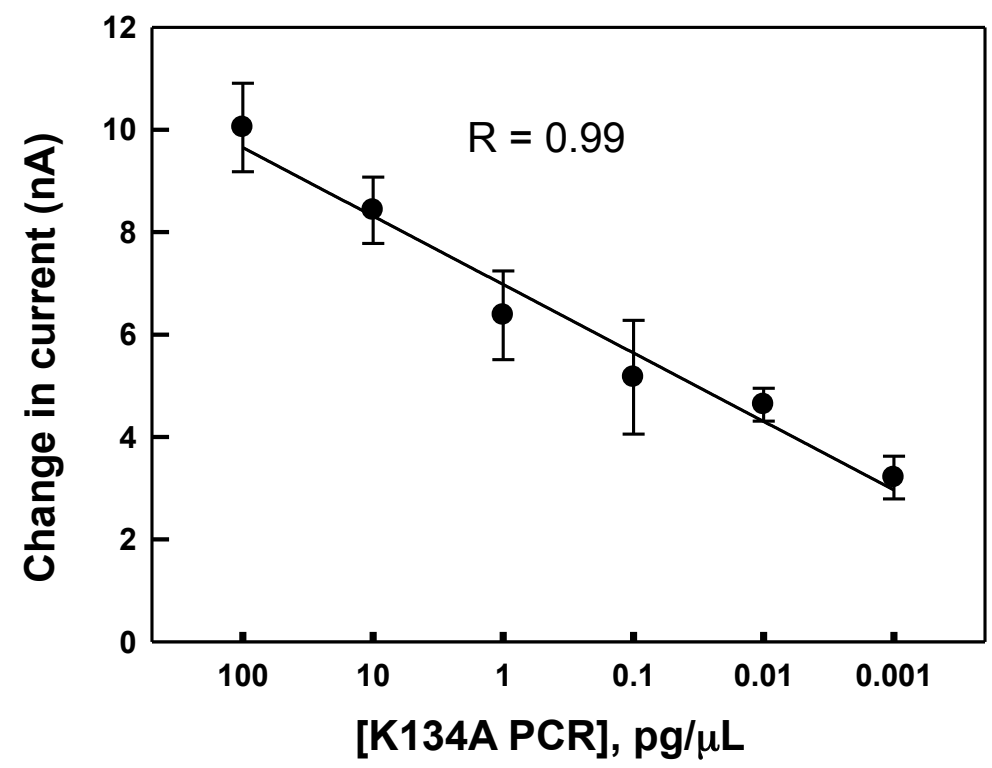

Supporting Figure 1. Concentration dependence of electrochemical DCP assay. KRAS mutant sensor. Concentration-dependent signal change for K134A PCR containing DCPs, clamp for WT, and $100 \mathrm{pg} / \mathrm{\mu L}$ of Wild type PCR at 134A mutant sensor. 


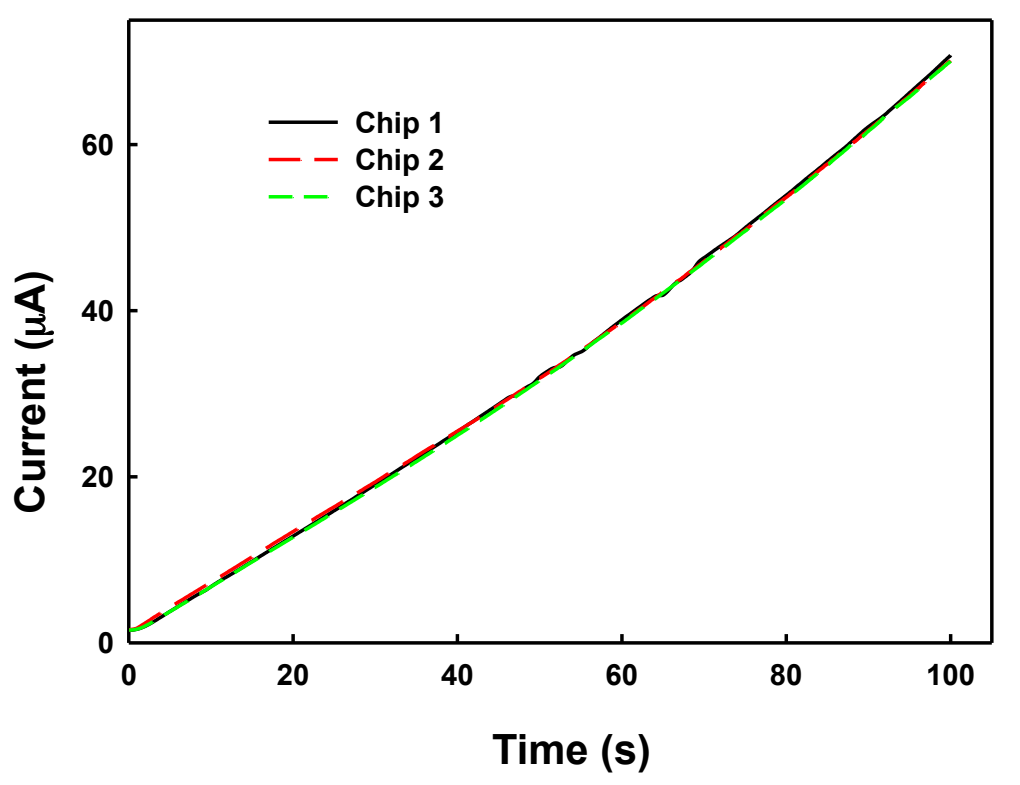

Supporting Figure 2. Au plating curves. DC potential amperometrogram were obtained at $0 \mathrm{mV}$ in $\mathrm{HAuCl}_{4}$ solution at three different chips for plating Au to grow Au-microstructure. 

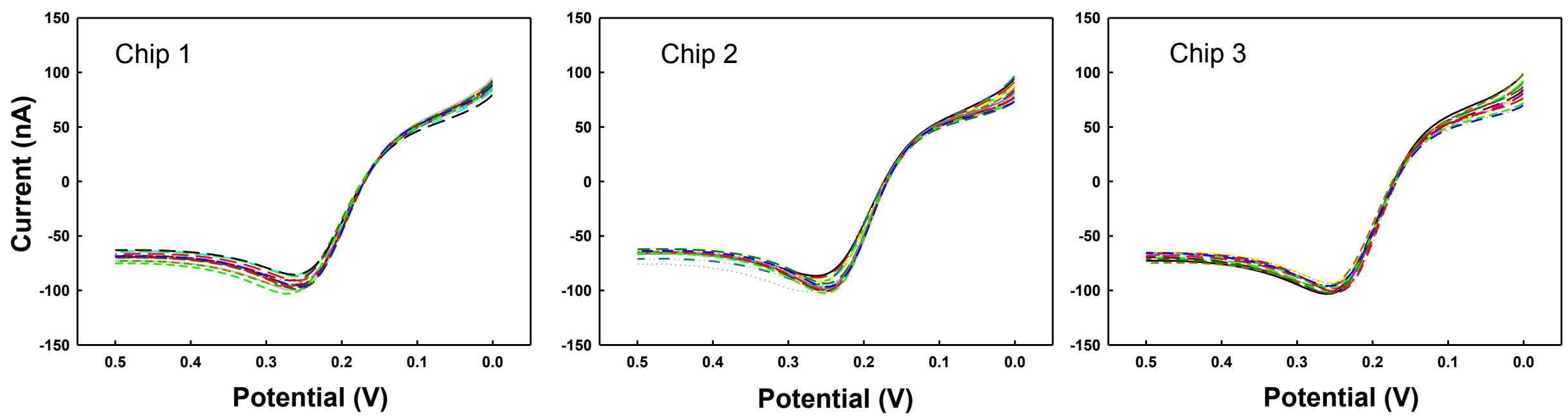

Supporting Figure 3. Comparison of different sensors at same and different chips. Linear sweep voltammograms were obtained in PBS solution containing $2.5 \mathrm{mM}\left[\mathrm{Fe}(\mathrm{CN})_{6}\right]^{3-}$ and $2.5 \mathrm{mM}\left[\mathrm{Fe}(\mathrm{CN})_{6}\right]^{4-}$. Mean current is $95.9 \mathrm{nA}$ with standard error $0.7 \mathrm{nA}$. 
Table S1. Melting temperature of different duplexes for KRAS detection.

\begin{tabular}{|l|c|}
\hline Duplex & Melting temperature ${ }^{\text {TM }}\left({ }^{\circ} \mathbf{C}\right)$ \\
\hline PNA probe / Target ss ctDNA & 86.4 \\
\hline DCP 5' / PNA probe & 52.9 \\
\hline DCP 3' / PNA probe & 41.9 \\
\hline DCP 5' / ss ctDNA & 82.0 \\
\hline DCP 3' / ss ctDNA & 85.7 \\
\hline
\end{tabular}

We calculated $\Delta G$ or melting temperature following a published paper (OligoCalc: an online oligonucleotide properties calculator, Nucleic Acids Res., 2007, Vol. 35, W43-W46; doi:10.1093/nar/gkm234). This online calculator gives parameters for DNA-DNA hybridization. It is known that PNA-DNA hybridization is stronger than DNA-DNA hybridization and approximately melting temperature is for PNA-DNA is $1^{\circ} \mathrm{C}$ higher for per base pair (http://pnabio.com/support/PNA_Tool.htm). 